\title{
EFFECT OF HELICOBACTER PYLORI ERADICATION ON HEPATIC STEATOSIS, NAFLD FIBROSIS SCORE AND HSENSI IN PATIENTS WITH NONALCOHOLIC STEATOHEPATITIS:
} a MR imaging-based pilot open-label study

\author{
Stergios A POLYZOS 1 , Panagiotis NIKOLOPOULOS ${ }^{2}$, Angeliki STOGIANNI ${ }^{3}$, \\ Iordanis ROMIOPOULOS ${ }^{1}$, Panagiotis KATSINELOS ${ }^{1}$ and Jannis KOUNTOURAS ${ }^{1}$
}

\begin{abstract}
Context - Limited clinical data suggest Helicobacter pylori $(H p)$ infection may contribute to nonalcoholic fatty liver disease (NAFLD) pathogenesis. Objective - The effect of $H p$ eradication on hepatic steatosis (magnetic resonance imaging), nonalcoholic fatty liver disease fibrosis score and HSENSI (Homocysteine, serum glutamic oxaloacetic transaminase, Erythrocyte sedimentation rate, nonalcoholic steatohepatitis Index) in nonalcoholic steatohepatitis patients. Methods - Thirteen adult patients with biopsy-proven nonalcoholic steatohepatitis, asymptomatic for gastrointestinal disease, underwent ${ }^{13} \mathrm{C}$ urea breath test; $H p$ positive patients received eradication therapy until repeat test become negative. Hepatic fat fraction, standard biochemical tests and calculation of nonalcoholic fatty liver disease fibrosis score and HSENSI were performed at baseline and month 12. Results - Hepatic fat fraction was similar for between and within group comparisons. Nonalcoholic fatty liver disease fibrosis score showed a non-significant trend towards decrease in $H p(+)$ [-0.34 (-1.39-0.29) at baseline and $-0.24(-0.99-0.71)$ at month $12 ; P=0.116]$, whereas increase in $H p(-)$ group [-0.38 (-1.72-0.11) and -0.56 (-1.43-0.46), respectively; $P=0.249]$. HSENSI was significantly decreased only in $H p(+)$ group [1.0 (1.0-2.0) at baseline and $1.0(0-1.0)$ at month $12 ; P=0.048]$. Conclusions - Hp eradication had no long-term effect on hepatic steatosis, but showed a trend towards improvement in nonalcoholic fatty liver disease fibrosis score and HSENSI. These results warrant larger studies with paired biopsies.
\end{abstract}

HEADINGS - Helicobacter pylori. Fatty liver. Magnetic resonance imaging.

\section{INTRODUCTION}

Nonalcoholic fatty liver disease (NAFLD) is considered to be the hepatic manifestation of insulin resistance (IR) or metabolic syndrome ${ }^{(8)}$, given that IR plays a key role in its pathogenesis ${ }^{(22)}$. NAFLD ranges from nonalcoholic simple steatosis (SS) to nonalcoholic steatohepatitis (NASH), whose features are steatosis, inflammation and fibrosis; advanced stages of NASH may ultimately result in liver cirrhosis with its complications, including hepatocellular carcinoma ${ }^{(26)}$. The prevalence of IR syndrome and its related morbidity is rapidly increasing worldwide ${ }^{(22)}$. Apart from the usual risk factors, such as sedentary lifestyle and dietary habits, exposure to other factors, including endocrine disruptors ${ }^{(18)}$ and Helicobacter pylori $(\mathrm{Hp})$ infection ${ }^{(23)}$, have been proposed as cofounders of the multi-faceted pathogenesis of IR.

Except for its conventional involvement in gastrointestinal diseases, $H p$ infection has been also implicated in a variety of extradigestive conditions, including cardiovascular, lung, hematologic, ophthalmic, skin, pancreatic, neurologic and hepatobiliary diseases ${ }^{(4,11}$. ${ }_{15,27}$. Regarding IR-related morbidity, $H p$ infection may be implicated in the pathogenesis of obesity and type 2 diabetes mellitus (T2DM) ${ }^{(4,11,27,29)}$. Limited clinical data also suggest that $H p$ infection might contribute to the pathogenesis of $\operatorname{NAFLD}^{(9,17,28)}$. We previously showed in an observational study that $H p$ infection may contribute to the pathogenesis NAFDL $^{(19)}$. If an association between $H p$ infection and NAFLD is validated, eradicating $H p$ infection

${ }^{1}$ Second Medical Clinic, Medical School, Aristotle University of Thessaloniki, Ippokration Hospital; ${ }^{2}$ Department of Radiology, 424 General Military Hospital; ${ }^{3}$ Department of Radiology, Ippokration Hospital. Thessaloniki, Macedonia, Greece.

Correspondence: Stergios A. Polyzos. 13 Simou Lianidi, 55134 Thessaloniki, Macedonia, Greece. E-mail: stergios@endo.gr 
might have therapeutic benefits in NAFLD treatment, which is currently an unmet need ${ }^{(24)}$.

Apart from the noninvasive indices of NAFLD fibrosis score and HSENSI [Homocysteine, serum glutamic oxaloacetic transaminase (SGOT), Erythrocyte sedimentation rate, Nonalcoholic Steatohepatitis Index] in NASH patients, there are also many noninvasive imaging modalities in the radiological armamentarium, namely, ultrasonography, computed tomography, and magnetic resonance imaging (MRI), to provide an accurate assessment of intrahepatic fat content ${ }^{(10,25)}$. Specifically, various MRI-based techniques, including chemical shift imaging (CSI), frequency-selective imaging and MR spectroscopy, are currently in clinical use for the detection and quantification of fat-water admixtures, with each technique having significant advantages, disadvantages, and limitations ${ }^{(25)}$. These techniques permit the breakdown of the net MR signal into fat and water signal components, permitting the quantification of fat in hepatic tissue, and are progressively being used in the diagnosis, therapy and follow up of NAFLD patients ${ }^{(6)}$.

In this respect, the primary endpoint of this pilot study was the effect of $H p$ eradication treatment on hepatic steatosis (MRI-based) and the noninvasive indices of NAFLD fibrosis score and HSENSI in NASH patients, asymptomatic for gastrointestinal disease. Secondary endpoint was the effect of $H p$ eradication treatment on anthropometric parameters, liver function tests and other NAFLD-related parameters.

\section{METHODS}

Eligible middle-aged, Caucasian adults, asymptomatic for gastrointestinal disease, were identified and recruited on an outpatient basis. The study was in accordance with the Declaration of Helsinki and the International Conference on Harmonization for Good Clinical Practice, and was approved by the local Ethics Committee. All the participants provided a written informed consent. Inclusion criteria were: 1) biopsyproven NASH according to NAFLD Activity Score (NAS $\geq 3)^{(13)}$; 2) no symptoms for gastrointestinal tract disease for at least a 12-month period before screening. Exclusion criteria were: 1) average daily ethanol consumption $>20 \mathrm{~g} /$ day; 2) liver cirrhosis or clinical evidence of decompensated chronic liver disease (ascites, current or previous hepatic encephalopathy, evidence of portal hypertensive haemorrhage or varices and portal hypertensive gastropathy on endoscopy); 3) other liver disease (viral hepatitis, autoimmune hepatitis, primary sclerosing cholangitis, primary biliary cirrhosis and overlap syndromes, drug-induced liver disease, hemochromatosis, Wilson's disease, $\alpha 1$-antitrypsin deficiency); 4) type 1 diabetes mellitus; 5) T2DM treated with insulin or thiazolidinediones; 6) pancreatitis; 7) uncontrolled hypothyroidism or hyperthyroidism; 8) adrenal insufficiency; 9) renal failure; 10) thrombotic disorders; 11) any malignancy; 12) breastfeeding or pregnancy; 13) addiction to any drug; 14) medical history of multiple drug allergies (defined as anaphylactoid drug reactions in $>2$ drug groups); 14) use of the following medications within a 12-month period before screening: any antibiotic, any proton pump inhibitor or any anti-acid or cimetidine, estrogens, progestins, glucocorticosteroids, insulin, thiazolidinediones, dipeptidy peptidase IV inhibitors and other GLP-1-based therapies, sibutramine, orlistat, rimonabant, phentermine, topiramate, vitamin E, multivitamins, ferrum, ursodeoxycholic acid, interferon, tamoxifene, methotrexate, amiodarone, biologic agents, any medication affecting hemostasis, such as antiplatelet agents, aspirin or oral anticoagulants.

At the screening visit, all patients underwent a ${ }^{13} \mathrm{C}$ urea breath test (Helicobacter INFAI test; INFAI GmbH, Bochum, Germany) and the analysis was carried out using an isotope ratio mass spectrometer (Faran Laboratories, Athens, Greece). Delta ${ }^{13} \mathrm{C}$ (between $\mathrm{T}_{0}$ min and $\mathrm{T}_{30} \mathrm{~min}$ ) $>4.0$ per mill at ${ }^{13} \mathrm{C}$ urea breath test was considered positive for $\mathrm{Hp}$ infection. According to this test, the patients positive for $\mathrm{Hp}$ infection were assigned to $H p(+)$ group, whereas the negative ones to $H p(-)$ group. The patients of $H p(+)$ group received $H p$ eradication treatment, whereas those of $H p(-)$ group were followed-up without treatment. All patients received standard instructions for diet and exercise.

At baseline, a complete medical history and blood samples were obtained, and physical examination and MRI were performed. Morning (8-9 am) fasting blood samples were collected before MRI. At month two ( \pm 2 weeks), the patients underwent a repeat ${ }^{13} \mathrm{C}$ urea breath test. Pills were also counted and the patients were asked for adverse events. At month 12 ( \pm 1 month), the patients were subjected to physical examination and repeat MRI. Blood samples were also obtained before MRI.

As first line $H p$ eradication standard triple therapy, amoxicillin ( $1 \mathrm{~g}$ twice daily for the initial 10 days), clarithromycin (500 $\mathrm{mg}$ twice daily for the initial 10 days) and omeprazole (20 $\mathrm{mg}$ twice daily for the initial 10 days followed by once daily for the subsequent 20 days) were introduced. Second-line $H p$ eradication therapy was administered in case of a positive ${ }^{13} \mathrm{C}$ urea breath test after the first line $H p$ eradication protocol. The second line $H p$ eradication consisted of amoxicillin $(1 \mathrm{~g}$ twice daily for the initial 10 days), metronidazole (500 $\mathrm{mg}$ twice daily for the initial 10 days), levofloxacin (500 mg once daily for the days 11-17) and omeprazole (20 mg twice daily for 1 month). In this case, ${ }^{13} \mathrm{C}$ urea breath test was repeated as necessary. Compliance was determined through questioning and recovery of empty medication envelopes. Adverse effects were evaluated by means of a questionnaire.

Hematologic and biochemical tests [hematocrit, hemoglobin, white blood cell (WBC) and subpopulation count, platelet count, SGOT, glutamic-pyruvic transaminase (SGPT), gamma-glutamyl transferase (GGT), alkaline phosphatase (ALP), total cholesterol, triglycerides, highdensity lipoprotein cholesterol (HDL-C), glucose, uric acid, creatinine, creatine phosphokinase (CPK) and albumin] and ESR were measured within $1 \mathrm{~h}$ after blood drawing, with standard methods using automated analyzers: Beckman Coulter LH 750 (Nyon, Switzerland) for hematologic tests; Olympus AU2700 (Olympus, Hamburg, Germany) for 
biochemical tests; and Ves Matic 20 (Menarini Diagnostics, Rungis, France) for ESR. Sera were also immediately frozen at $-30^{\circ} \mathrm{C}$ for the measurement of ferritin and homocysteine, which were measured in one batch at the end of the study with immuno-chemiluminescence on an ADVIA Centaur immunoassay system (Siemens Healthcare Diagnostics, Deerfield, IL; homocysteine: intra-assay CV 2.3\%-4.4\%, inter-assay CV $1.5 \%-5.2 \%$; ferritin: intra-assay CV $2.1 \%-3.0 \%$, inter-assay CV $2.7 \%-5.4 \%$ ).

MRI was performed on a 1.5 Tesla clinical MR Imaging system (MAGNETOM Avanto Tim, Siemens, Munich, Germany) with a Q-engine $(33 \mathrm{mT} / \mathrm{m}, 125 \mathrm{~T} / \mathrm{m} / \mathrm{s})$ and a 4-channel phased array body coil. Two-points Dixon quantification method was used to interpret the liver steatosis. This quantification method is based on T1 weighted echo gradient sequences of the liver allowing in phase (IP) and opposed phase (OP) images. Fat calculation was carried out from the signal intensities measured in the regions of interest (ROI), located in the right liver lobe (anterior or posterior right liver lobes). The ROI in most of the cases corresponded to the biopsy location. ROIs were attentively placed to avoid liver vessels. Fat fraction (HFF) was calculated using the following equation:

$$
\mathrm{HFF} \%=\frac{I P-O P}{2 I P} \times 100
$$

All MRI scans were interpreted and HFF was calculated by two experienced radiologists (A.S, P.N.), as previously reported ${ }^{(7)}$; the radiologists were blinded to the patients' history and tests.

Body mass index (BMI) was calculated by the formula body weight $[\mathrm{kg}] /$ height $^{2}[\mathrm{~m}]$. Low-density lipoprotein (LDL-C) was calculated with the formula of Friedewald. Waist-to-Hip ratio (WHR) and SGOT/SGPT ratio was also calculated. NAFLD fibrosis score was calculated by the equation of Angulo et al. ${ }^{(2)}$. NASH was quantified by the index HSENSI, as previously proposed ${ }^{(20)}$.

\section{Statistical analysis}

Data for continuous variables are presented as median (interquartile range). Data for categorical variables are presented as frequencies. Non-parametric tests were mainly used, because of the small sample size. Mann-Whitney test was used for between group comparisons of continuous variables. Wilcoxon signed ranks test was used for within group comparisons of continuous variables. Chi-square test or Fischer's exact test were used for the comparisons of categorical variables. Partial coefficient ( $\left.r_{p}\right)$ was used for binary correlations adjusted for group. Multiple linear regression analysis («enter» method) was used to identify variables independently associated with HFF at baseline or month 12 . Independent variables that were not normally distributed were logarithmically transformed for the need of this analysis. The analyses were on treatment. A two-sided p-value of less than 0.05 was considered statistically significant in all the above tests. Statistical analysis was performed by SPSS 21.0 for Macintosh (IBM Corp., Armonk, NY).

\section{RESULTS}

Thirteen adult patients ( 3 men, 10 women) with biopsyproven NASH were recruited in this pilot study. Six patients were found to be positive for $H p$ infection according to the ${ }^{13} \mathrm{C}$ urea breath test and were assigned to $H p(+)$ group, whereas the remaining seven patients were negative and assigned to $H p(-)$ group. One patient of the $H p(-)$ group discontinued the study before completion: at six post-baseline month she complained for abdominal discomfort and she was subjected to repeat ${ }^{13} \mathrm{C}$ urea breath test and upper gastrointestinal endoscopy-gastric histology, which were both positive for $H p$ infection. One patient of $H p(+)$ group remained positive after the first line eradication protocol and a second line therapy introduced to become negative. No adverse event was reported. Pill count at month 2 visit showed an acceptable compliance, with a mean consumption rate of $93 \%$.

At baseline, $H p(+)$ and $H p(-)$ group had similar age [61.6 (54.5-70.5) and 57.5 (51.2-63.8) years, respectively; $P=0.469]$ and duration of persistent transaminasemia [6.5 (5.8-8.3) and 9.0 (7.0-12.0) years, respectively; $P=0.198]$. Furthermore, BMI, waist and hip circumference and WHR were also similar between groups at baseline (Table 1), as well as the frequency of impaired fasting glucose or T2DM (four patients in each group; $P=1.000$ ).

Comparative data of both groups at baseline and month 12 are presented in Table 1. HFF was similar for between and within group comparisons. NAFLD fibrosis score showed a non-significant trend towards decrease in $H p(+)$, whereas increase in $H p(-)$ group. HSENSI was significantly decreased only in $H p(+)$ group. Furthermore, WBC were significantly decreased in $H p(+)$ group, but not $H p(-)$ group; this could be mainly attributed to a trend towards decrease in granulocytes. ESR was significantly increased and triglycerides were decreased only in $H p(-)$ group. The remaining parameters, including liver function tests, glucose, uric acid, ferritin and homocysteine remained essentially unchanged (Table 1).

When adjusted for group $[H p(+)$ or $H p(-)]$, HFF at baseline and month 12 were highly correlated $\left(\mathrm{r}_{\mathrm{p}}=0.927\right.$; $P<0.001)$. At baseline, HFF showed a trend towards significant correlation with lymphocyte count $\left(\mathrm{r}_{\mathrm{p}}=0.601 ; P\right.$ $=0.051)$ and fasting glucose $\left(\mathrm{r}_{\mathrm{p}}=0.564 ; P=0.071\right)$. HFF was not correlated with other study parameters. In multiple linear regression analysis at baseline, HFF was associated with fasting glucose $(\mathrm{B}=0.663 ; P=0.042)$, independently from group, age, waist circumference, SGOT/SGPT ratio and lymphocyte count; notably, HFF was not independently associated with current $H p$ infection at baseline. In a similar model of regression, HFF at month 12 was independently associated only with HFF at baseline $(\mathrm{B}=0.949 ; P=0.015)$ independently from eradication therapy, age, waist circumference, SGOT/SGPT ratio glucose and albumin at month 12; notably, HFF at month 12 was not independently associated with $H p$ eradication treatment.

When adjusted for group, NAFLD fibrosis score at baseline and month 12 were highly correlated $\left(r_{p}=0.891\right.$; $P<0.001)$. On the other hand, HSENSI at month 12 was not 
TABLE 1. Baseline and 12-month comparative data between $H p(+)$ and $H p(-)$ groups

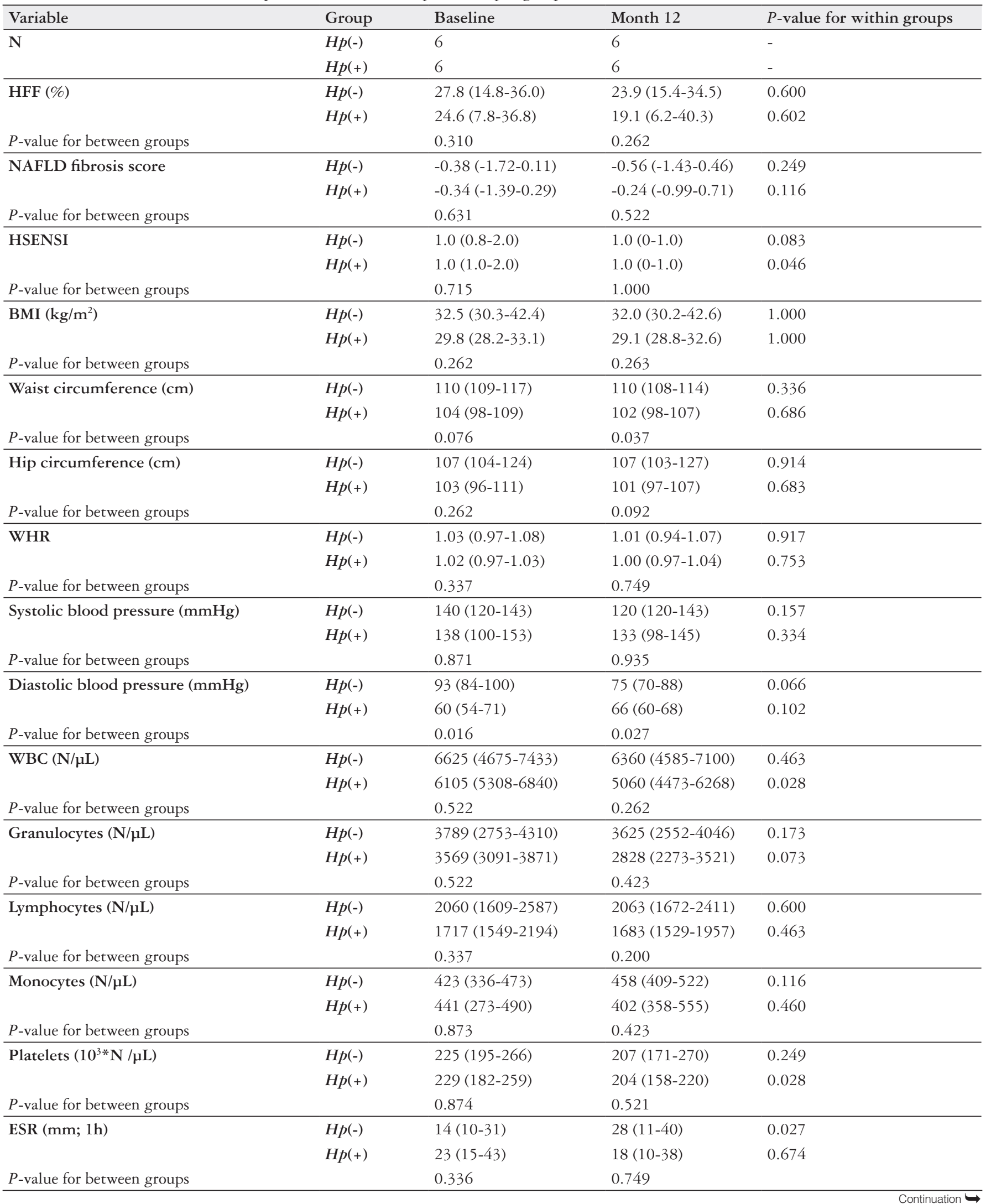




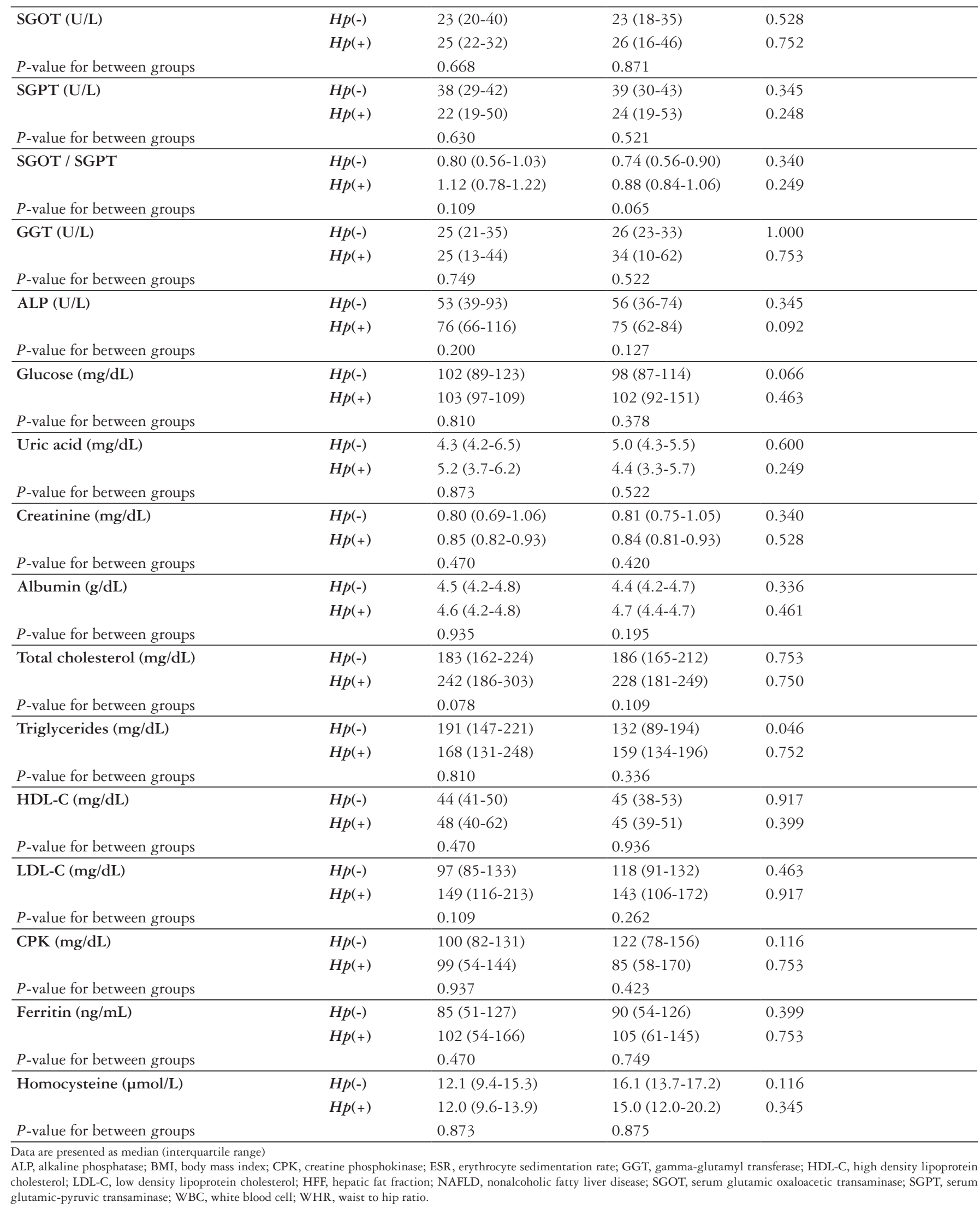


associated to baseline values (chi-square $=4.286 ; P=0.117$ ). At baseline, NAFLD fibrosis score was significantly correlated with age $\left(\mathrm{r}_{\mathrm{p}}=0.641 ; P=0.034\right)$. NAFLD fibrosis score was not correlated with other study's parameters. We did not perform multiple regression analysis for NAFLD fibrosis score at baseline or month 12 , because the only parameters which provided $P<0.1$ at partial correlations were those included in the equation for the calculation of NAFLD fibrosis score.

\section{DISCUSSION}

This pilot study showed no long-term effect of $H p$ eradication treatment on hepatic steatosis, assessed by MRI; on the other hand, NAFLD fibrosis score and HSENSI showed a trend towards decrease in $H p(+)$ group, which was statistically significant for HSENSI. The short-term effect of $H p$ eradication therapy on hepatic steatosis and fibrosis indices was beyond the scope of this study; we selected to evaluate it on a long-term basis because: a) fibrosis is not expected to reduce shortly after any treatment ${ }^{(24)}$; and b) even if $\mathrm{Hp}$ eradication therapy was beneficial on a short-term basis, this would not have any clinical implication if was not persistent on a long-term basis.

To the best of our knowledge, this is the first MRI-based study evaluating the effect of $H p$ eradication treatment on hepatic steatosis, and fibrosis indices. Similarly to our findings, Jamali et al. reported that $H p$ eradication treatment had no 8-week and 24-week effect on hepatic fat content of dyspeptic NAFLD patients ${ }^{(12)}$. Despite similar results, that study was designed differently than ours: 1) hepatic fat content was calculated by the equation proposed by Kotronen et al. (the noninvasive index «NAFLD liver fat score») $)^{(14)}$, whereas directly by MRI in our study; 2 ) the included patients had ultrasound-proven NAFLD, whereas biopsy-proven NASH in our study; 3 ) the included patients were dyspeptic, whereas asymptomatic in our study; 4 ) the control group consisted of $H p(+)$ patients not assigned to treatment, whereas control group consisted of $H p(-)$ patients in our study.

HFF at baseline was independently associated with fasting glucose, which is pathogenetically expected, because dysregulation of glucose metabolism is associated with hepatic steatosis and, inversely, hepatic steatosis may lead to dysregulation of glucose metabolism ${ }^{(22)}$. Other authors have reported that 2-h glucose rises with increasing HFF (MRI) in a cross-sectional study of obese adolescents ${ }^{(5)}$. In a 4-year retrospective longitudinal study, the incidence of newly developed T2DM was higher in the NAFLD $(9.9 \%)$ compared with the non-NAFLD group (3.7\%) and a combined effect of impaired fasting glucose and NAFLD on the incidence of T2DM was shown ${ }^{(3)}$.

Interestingly, WBC were significantly decreased in $H p(+)$, but not $H p(-)$ group, owing mainly to trend towards decrease in granulocytes. In a previous cross-sectional study, higher
WBC count was reported to be associated with NAFLD (ultrasonographically-proven) independently from classical cardiovascular risk factors and other components of IR syndrome ${ }^{(16)}$. Other authors have proposed that higher granulocyte (neutrophil) to lymphocyte ratio (NLP) may be a noninvasive predictor of advanced $\mathrm{NASH}^{(1)}$.

NAFLD fibrosis score and HSENSI showed a trend towards decrease in $H p(+)$ group, which might be interpreted as a potentially beneficial effect of $H p$ eradication therapy on hepatic fibrosis and NASH, respectively. The changes in HSENSI could be mainly attributed to the increase in ESR only in the $H p(-)$ group, since SGOT and homocysteine showed similar trends between groups (Table 1). Although these results should be interpreted with caution, because both indices are not validated for long-term follow up, larger studies with repeat paired biopsies are warranted.

There are only limited clinical data regarding the association between $H p$ infection and NAFLD ${ }^{(9,17,19,28)}$. The presence of $16 \mathrm{~S}$ recombinant RNA of $H p$ spp. on liver samples of a patient with NASH has been initially reported ${ }^{(9)}$. This finding was validated by another study, in which the $16 \mathrm{~S}$ recombinant RNA was found in 5/11 liver samples of NAFLD patients compared with $2 / 13$ controls ${ }^{(17)}$. However, it remains unclear whether $H p$ in these specimens is an incidental finding or it has the potential to affect the natural course of NAFLD. We previously showed in an observational study ${ }^{(19)}$, that $H p$ infection may represent one more hit contributing in the pathogenesis of NAFLD, considered a multiple-hit disease ${ }^{(21)} ; H p$ infection may trigger TNF- $\alpha$, whereas adiponectin is secondarily increased to counterbalance the pro-inflammatory cascade. This may be achieved directly or indirectly, through $H p$-related increase in $\mathrm{IR}^{(19)}$. Takuma also reported in Japanese that $H p$ infection was one of the independent risk factors for the development of NAFLD ${ }^{(28)}$.

Regarding the study's secondary endpoint, anthropometric parameters, blood pressure, liver function tests, lipid profile, ferritin and homocysteine remained essentially unchanged in either group, with the exception of triglycerides, which were paradoxically decreased only in $H p(-)$ group. Similar to our findings, Jamal et al. showed no effect of $H p$ eradication treatment on lipid profile, insulin resistance, and anthropometric measurements in dyspeptic NAFLD patients, eight and 24 weeks post-treatment ${ }^{(12)}$.

This study has certain limitations. First, the sample size was small, given that this was a pilot study; although the diagnosis of NASH was histologically confirmed, the interpretation of the results warrants large-scale research before drawing definite conclusions. Second, $H p$ was not investigated in liver histological specimens. Third, the diagnosis of $H p$ infection was not established by culture or histology, representing the practical diagnostic gold standard of $H p$ infection; however, this would meet ethical considerations, because the patients were asymptomatic for gastrointestinal diseases; instead, ${ }^{13} \mathrm{C}$ urea breath test was used as a safe, 
noninvasive and reliable method for the diagnosis of $\mathrm{Hp}$ infection. Fourth, repeat liver biopsy, which would be the ideal gold standard for pairwise comparison of steatosis and fibrosis, was not performed, because of ethical considerations. Furthermore, the study was not placebo-controlled, due to our inability to produce placebo pills similar to therapeutic ones. Finally, although HSENSI has been proposed as a noninvasive index for $\mathrm{NASH}^{(20)}$, it has not been externally validated yet.

\section{CONCLUSIONS}

$H p$ eradication treatment had no long-term effect on hepatic steatosis assessed by MRI, but showed a trend towards improvement in NAFLD fibrosis score and HSENSI, which are also noninvasive indices of hepatic fibrosis and NASH, respectively. Although these results should be interpreted with caution, mainly because of the small sample size of this pilot study, larger studies with repeat paired biopsies are warranted.

Polyzos SA, Nikolopoulos P, Stogianni A, Romiopoulos I, Katsinelos P, Kountouras J. O efeito da erradicação do Helicobacter pylori na esteatose hepática, no escore de fibrose na DHNA e o HSENSI em pacientes com esteatohepatite não alcoólica: um estudo piloto aberto baseado em ressonância magnética. Arq Gastroenterol. 2014,51(3):261-8.

RESUMO - Contexto - Dados clínicos limitados sugerem que infecção por Helicobacter pylori (Hp) pode contribuir para a patogênese da doença hepática gordurosa não alcoólica. Objetivo - Verificar o efeito da erradicação do $H p$ na esteatose hepática pela ressonância magnética, na pontuação da fibrose na doença hepática gordurosa não alcoólica e no HSENSI (homocisteína, transaminase glutâmico oxalacética no soro, taxa de sedimentação de eritrócitos, Indice NASH na esteatohepatite não-alcoólica) em pacientes com esteato-hepatite não alcoólica. Métodos - Treze pacientes adultos com esteato-hepatite não alcoólica comprovada por biópsia, assintomáticos para a doença gastrointestinal, submetidos ao $1^{13} \mathrm{C}$ teste respiratório da ureia ${ }^{13} \mathrm{C}$. Pacientes $H p$ positivos receberam terapia de erradicação até repetição do teste tornar-se negativa. A fração de gordura hepática, testes bioquímicos padrão e cálculo da pontuação da fibrose e esteatose hepática HSENSI foram realizados no início e no mês 12. Resultados - A fração de gordura hepática foi similar entre e dentro das comparações entre os grupos. A pontuação da fibrose na doença hepática gordurosa não alcoólica mostrou uma tendência não significativa para diminuição no grupo $H p(+)[-0,34(-1,39-0,29)$ no início do estudo e $-0,24(-0,99-0,71)$ no 12 mês; $P=0,116]$, enquanto aumentaram no grupo $\mathrm{Hp}(-)[-0.38(-1,72-0,11)$ e $-0,56(-1,43-0,46)$, respectivamente; $P=0,249]$. O HSENSI diminuiu significativamente apenas no grupo $\mathrm{Hp}(+)\left[1,0(1,0-2,0)\right.$ na linha de base e $1,0(0-1,0)$ no $12^{\circ}$ mês; $\left.P=0,048\right]$. Conclusões - A erradicação do $H p$ não teve efeito de longo prazo sobre a esteatose hepática, mas mostrou uma tendência de melhora na pontuação da fibrose e esteatose hepática HSENSI. Estes resultados justificam maiores estudos com biópsias pareadas.

DESCRITORES - Helicobacter pylori. Fígado gorduroso. Imagem por ressonância magnética. 


\section{REFERENCES}

1. Alkhouri N, Morris-Stiff G, Campbell C, Lopez R, Tamimi TA, Yerian L, et al. Neutrophil to lymphocyte ratio: a new marker for predicting steatohepatitis and fibrosis in patients with nonalcoholic fatty liver disease. Liver Int. 2012;32:297-302.

2. Angulo P, Hui JM, Marchesini G, Bugianesi E, George J, Farrell GC, et al. The NAFLD fibrosis score: a noninvasive system that identifies liver fibrosis in patients with NAFLD. Hepatology. 2007;45:846-54.

3. Bae JC, Rhee EJ, Lee WY, Park SE, Park CY, Oh KW, et al. Combined effect of nonalcoholic fatty liver disease and impaired fasting glucose on the development of type 2 diabetes: a 4-year retrospective longitudinal study. Diabetes Care. 2011;34:727-9.

4. Banic M, Franceschi F, Babic Z, Gasbarrini A. Extragastric manifestations of Helicobacter pylori infection. Helicobacter. 2012;17 Suppl 1:49-55.

5. Cali AM, De Oliveira AM, Kim H, Chen S, Reyes-Mugica M, Escalera S, et al Glucose dysregulation and hepatic steatosis in obese adolescents: is there a link? Hepatology. 2009;49:1896-903.

6. Cassidy FH, Yokoo T, Aganovic L, Hanna RF, Bydder M, Middleton MS, et al. Fatty liver disease: MR imaging techniques for the detection and quantification of liver steatosis. Radiographics. 2009;29:231-60.

7. Cesbron-Metivier E, Roullier V, Boursier J, Cavaro-Menard C, Lebigot J, Michalak $\mathrm{S}$, et al. Noninvasive liver steatosis quantification using MRI techniques combined with blood markers. Eur J Gastroenterol Hepatol. 2010;22:973-82.

8. Chen SH, He F, Zhou HL, Wu HR, Xia C, Li YM. Relationship between nonalcoholic fatty liver disease and metabolic syndrome. J Dig Dis. 2011;12:125-30.

9. Cindoruk M, Cirak MY, Unal S, Karakan T, Erkan G, Engin D, et al. Identification of Helicobacter species by $16 \mathrm{~S}$ rDNA PCR and sequence analysis in human liver samples from patients with various etiologies of benign liver diseases. EurJ Gastroenterol Hepatol. 2008;20:33-6.

10. d'Assignies G, Fontés G, Kauffmann C, Latour M, Gaboury L, Boulanger Y, et al. Early detection of liver steatosis by magnetic resonance imaging in rats infused with glucose and intralipid solutions and correlation to insulin levels. Metabolism. 2013;62:1850-7.

11. Figura N, Franceschi F, Santucci A, Bernardini G, Gasbarrini G, Gasbarrin A. Extragastric manifestations of Helicobacter pylori infection. Helicobacter. 2010;15 Suppl 1:60-8.

12. Jamali R, Mofid A, Vahedi H, Farzaneh R, Dowlatshahi S. The effect of helicobacter pylori eradication on liver fat content in subjects with non-alcoholic Fatty liver disease: a randomized open-label clinical trial. Hepat Mon. 2013;13:e14679.

13. Kleiner DE, Brunt EM, Van NM, Behling C, Contos MJ, Cummings OW, et al. Design and validation of a histological scoring system for nonalcoholic fatty liver disease. Hepatology. 2005;41:1313-21.
14. Kotronen A, Peltonen M, Hakkarainen A, Sevastianova K, Bergholm R, Johansson LM, et al. Prediction of non-alcoholic fatty liver disease and liver fat using metabolic and genetic factors. Gastroenterology. 2009;137:865-72.

15. Kountouras J, Zavos C, Chatzopoulos D. A concept on the role of Helicobacter pylori infection in autoimmune pancreatitis. J Cell Mol Med. 2005;9:196-207.

16. Lee YJ, Lee HR, Shim JY, Moon BS, Lee JH, Kim JK. Relationship between white blood cell count and nonalcoholic fatty liver disease. Dig Liver Dis. 2010;42: 888-94.

17. Pirouz T, Zounubi L, Keivani H, Rakhshani N, Hormazdi M. Detection of Helicobacter pylori in paraffin-embedded specimens from patients with chronic liver diseases, using the amplification method. Dig Dis Sci. 2009;54:1456-9.

18. Polyzos SA, Kountouras J, Deretzi G, Zavos C, Mantzoros CS. The emerging role of endocrine disruptors in pathogenesis of insulin resistance: a concept implicating nonalcoholic fatty liver disease. Curr Mol Med. 2012;12:68-82.

19. Polyzos SA, Kountouras J, Papatheodorou A, Patsiaoura K, Katsiki E, Zafeiriadou $\mathrm{E}$, et al. Helicobacter pylori infection in patients with nonalcoholic fatty liver disease. Metabolism. 2013;62:121-6.

20. Polyzos SA, Kountouras J, Slavakis A, Zafeiriadou E, Patsiaoura K, Katsiki E et al. A novel noninvasive index for nonalcoholic steatohepatitis: a pilot study. Biomarkers. 2013;18:607-13.

21. Polyzos SA, Kountouras J, Zavos C. The multi-hit process and the antagonistic roles of tumor necrosis factor-alpha and adiponectin in nonalcoholic fatty liver disease. Hippokratia. 2009;13:127.

22. Polyzos SA, Kountouras J, Zavos C. Nonalcoholic fatty liver disease: the pathogenetic roles of insulin resistance and adipocytokines. Curr Mol Med. 2009;72:299-314.

23. Polyzos SA, Kountouras J, Zavos C, Deretzi G. The association between Helicobacter pylori infection and insulin resistance: A systematic review. Helicobacter. 2011;16:79-88

24. Polyzos SA, Kountouras J, Zavos C, Deretzi G. Nonalcoholic fatty liver disease: Multimodal treatment options for a pathogenetically multiple-hit disease. J Clin Gastroenterol. 2012;46:272-84.

25. Polyzos SA, Mantzoros CS. Necessity for timely noninvasive diagnosis of nonalcoholic fatty liver disease. Metabolism. 2014;63:161-7.

26. Schuppan D, Schattenberg JM. Non-alcoholic steatohepatitis: Pathogenesis and novel therapeutic approaches. J Gastroenterol Hepatol. 2013;28:68-76.

27. Suzuki H, Franceschi F, Nishizawa T, Gasbarrini A. Extragastric manifestations of Helicobacter pylori infection. Helicobacter. 2011;16 Suppl 1:65-9.

28. Takuma Y. Helicobacter pylori infection and liver diseases. Gan To Kagaku Ryoho. 2011;38:362-4

29. Zhou X, Zhang C, Wu J, Zhang G. Association between Helicobacter pylori infection and diabetes mellitus: a meta-analysis of observational studies. Diabetes Res Clin Pract. 2013;99:200-8. 